\title{
UPAYA PENINGKATAN KEPUASAN PASIEN DI INSTALASI FARMASI RUMAH SAKIT ISLAM SURABAYA TAHUN 2016
}

\author{
Adiska Lina Arifiyanti, Rachmad Djamaludin* \\ *Prodi Administrasi Rumah Sakit STIKES Yayasan Rumah Sakit Dr.Soetomo \\ Jl. Karangmenjangan No. 12 Surabaya \\ Email : adiskalina.09@gmail.com
}

\begin{abstract}
ABSTRAK
Persepsi terhadap kepuasan yang dirasakan oleh setiap individu tentu tidak akan sama. Terlebih lagi kepuasan yang dirasakan dalam fungsi pelayanan pada rumah sakit yang diberikan kepada pasien.Penelitian ini bertujuan untuk mengetahui tingkat kepuasan pasien pada Rumah Sakit Islam Surabaya ditinjau dari faktor kehandalan, jaminan, bukti fisik, empati, dan daya tanggap di Instalasi Farmasi Rumah Sakit Islam Surabaya. Penelitian ini merupakan penelitian deskriptif. Penelitian ini dilakukan selama 5 hari pada bulan Juni 2016 di Instalasi farmasi Rumah Sakit Islam Surabaya. Populasi dalam penelitian ini adalah seluruh pasien di Instalasi Farmasi Rumah Sakit Islam Surabaya dan sampel yang diambil sebanyak 50 responden dari para pasien di Instalasi Farmasi Rumah Sakit Islam Surabaya dengan pendekatan accidental sampling.

Pengumpulan data diambil dengan menggunakan metode kuesioner dengan menggunakan skala likert.Berdasarkan hasil penelitian diketahui persepsi pasien merasa puas tentang kehandalan sebesar (69,5\%) untuk pasien yang merasa kurang puas sebesar (30,5\%). Persepsi pasien puas tentang jaminan sebesar $(73,5 \%)$ namun pasien kurang puas sebesar (26,5\%). Persepsi pasien yang menyatakan puas akan bukti fisik sebesar (75,5\%) dan pasien yang menyatakan kurang puas sebesar (24,5\%). Persepsi pasien puas tentang empati sebesar (72\%) untuk pasien kurang puas sebesar (28\%). Persepsi pasien yang menyatakan puas akan daya tanggap sebesar (53\%) sedangkan untuk persepsi pasien yang menyatakan kurang puas sebesar (47\%). Hasil yang diperoleh dari pelitian ini, bahwa sebagian besar menyatakan puas dengan tebaran antara 69,50 \% s/d 75,50 \%, kecuali pada faktor daya tanggap dinyatakan cukup puas.Kesimpulan penelitian ini adalah bahwa pelayanan yang diberikan di Instalasi Farmasi Rumah Sakit Islam Surabaya kepada pasien dikategorikan baik. Saran dari penilitian ini adalah dilakukan pelatihan soft skillberupa pelatihan kepribadian secara periodik, dilakukan pelatihan kecepatan waktu pelayanan kefarmasian dengan model simulasi serta melakukan pendataan secara konkrit atas ketersediaan obat berdasarkan tingkat kebutuhan pasien.
\end{abstract}

Kata Kunci : Pelayanan, Kepuasan, Persepsi.

\section{ABSTRACT}

The perception of the customer satisfaction felt by each individual would not be the same. Moreover satisfaction felt in the function of the ministry on the hospital given to patients. This research aims to know the level of satisfaction patients on Islamic Hospital Surabaya reviewed factor of reliability, assurance, tangible, empathy and responsiveness in the installation of Pharmacy Islamic Hospital Surabaya.This research is a descriptive research. This research was done for 5 days in June 2016 in pharmaceutical Installation Islamic Hospital Surabaya. The population in this research is all patients in Pharmaceutical 
Installation Islamic Hospital Surabaya and samples taken by 50 respondents from patients in the Pharmaceutical Installation Islamic Hospital Surabaya with sampling forcible entry approach. The collection of data taken using the method of the questionnaire using likert scale.Based on the results of research known to the perception of patients satisfied about the reliability of $(69,5 \%)$ for patients who feel less satisfied by (30.5\%). The perception of patients satisfied about the assurance of (73.5\%) but patients less satisfied by (26,5\%). Patients perception that states satisfied with the tangible of $(75,5 \%)$ and patients who stated that less satisfied by (24.5\%).

The perception of patients satisfied about the empathy of (72\%) for patients with less satisfied by (28\%). The perception of patients who felt satisfied will responsiveness of (53\%) while for the perception of patients who stated that less satisfied by (47\%). The results obtained from this pelitian, that most states satisfied between $69,50 \% \mathrm{~s} / \mathrm{d} 75,50 \%$, except on power factor stated response satisfied.The conclusion of this research is that the services provided in the installation of Pharmacy Islamic Hospital Surabaya to patients are categorized as well. Suggestions from an extensive microinsurance is conducted training soft skills in the form of training periodically personality, conducted training time speed pharmaceutical services with simulation models and perform files collection in the concrete on the availability of drugs based on the level of needs of patients.

Keywords : Services, Satisfaction, Perception.

\section{PENDAHULUAN}

Kesehatanmerupakan salah satu unsur kesejahteraan umum yang harus dapat diwujudkan melalui pembangunan yang berkesinambungan. Pembangunan kesehatan merupakan salah satu upaya pembangunan nasional diarahkan guna tercapainya kesadaran, kemauan, dan kemampuan hidup sehat bagi setiap orang agar terwujud derajat kesehatan masyarakat yang optimal (Depkes RI, 2002).

Kesehatan juga merupakan hal yang penting bagi umat manusia. Hal ini dikarenakan kesehatan merupakan salah satu faktor yang menunjang kualitas hidup manusia. Agar tercipta masyarakat yang produktif, peningkatan kualitas hidup manusiapun harus dilakukan. Salah satu cara untuk meningkatkan kualitas hidup manusia adalah dengan meningkatkan kualitas pelayanan kesehatan. Hal ini menuntut penyedia jasa layanan kesehatan seperti rumah sakit untuk lebih meningkatkan kualitas pelayanan yang lebih baik.

Berdasarkan Undang - Undang Nomor 44 Tahun 2009 tentang Rumah Sakit, yang dimaksudkan dengan rumah sakit adalah institusi pelayanan kesehatan yang menyelenggarakan pelayanan kesehatan perorangan secara paripurna yang menyediakan pelayanan rawat inap, rawat jalan, dan gawat darurat.

Menurut Peraturan Menteri Kesehatan Republik Indonesia Nomor 58 tahun 2014, rumah sakit adalah institusi pelayanan kesehatan yang menyelenggarakan 
pelayanan kesehatan perorangan secara paripurna yang menyediakan pelayanan rawat inap, rawat jalan, dan gawat darurat. Rumah sakit juga dapat berfungsi sebagai tempat untuk mengembangkan ilmu medis dan penyakit serta mengembangkan pelayanan obat bagi pasien. Rumah sakit diharuskan memberi pelayanan dengan kualitas yang baik agar kepuasan pasien dapat tercapai.

Rumah sakit juga merupakan tempat menyelenggarakan upaya kesehatan yaitu setiap kegiatan untuk memelihara dan meningkatkan kesehatan serta bertujuan untuk mewujudkan derajat kesehatan yang optimal bagi masyarakat. Upaya kesehatan dilakukan dengan pendekatan pemeliharaan, peningkatan kesehatan (promotif), pencegahan penyakit (preventif), penyembuhan penyakit (kuratif) dan pemulihan (rehabilitatif) yang dilaksanakan secara serasi dan terpadu serta berkesinambungan (Siregar, 2004).

Berdasarkan Peraturan Pemerintah Republik Indonesia Nomor 51 Tahun 2009 tentang Pekerjaan Kefarmasian yang dimaksud dengan pelayanan kefarmasian adalah suatu pelayanan langsung dan bertanggung jawab kepada pasien yang berkaitan dengan sediaan farmasi dengan maksud mencapai hasil yang pasti untuk meningkatkan mutu kehidupan pasien. Pelayanan kefarmasian sebagai salah satu unsur dari pelayanan utama di rumah sakit, merupakan bagian yang tidak dapat dipisahkan dari sistem pelayanan di rumah sakit yang berorientasi kepada pelayanan pasien, penyediaan obat yang bermutu, termasuk pelayanan farmasi klinik yang terjangkau bagi semua lapisan masyarakat. Praktek pelayanan kefarmasian merupakan kegiatan terpadu, dengan tujuan untuk mengidentifikasi, mencegah dan menyelesaikan masalah yang berkaitan dengan obat dan kesehatan.

Pelayanan farmasi rumah sakit merupakan salah satu kegiatan di rumah sakit yang menunjang pelayanan kesehatan yang bermutu. Hal tersebut di perjelaskan dalam Keputusan Menteri Kesehatan Nomor 1333/Menkes/SK/XII/1999 tentang Standar Pelayanan Rumah Sakit, yang menyebutkan bahwa pelayanan farmasi rumah sakit adalah bagian yang tidak terpisahkan dari sistem pelayanan kesehatan rumah sakit yang berorientasi kepada pelayanan pasien, penyedian obat yang bermutu, termasuk pelayanan farmasi klinik, yang tejangkau bagi semua lapisan masyarakat.

Dilihat dari perspektif pasien, konsep kualitas terbagi menjadi dua yaitu kualitas yang berhubungan dengan pelayanan yang diterima oleh pasien dan kualitas yang berhubungan dengan kualitas hidup atau kepuasan pasien setelah memperoleh suatu intervensi (Shi\&Singh, 2005). Kualitas berperan sebagai indikator dari kepuasan 
berdasarkan pengalaman seseorang dalam menerima atau memperoleh suatu pelayanan kesehatan.

Pengukuran kepuasan pasien adalah salah satu pendekatan untuk mengukur kualitas suatu pelayanan. Kepuasan merupakan perasaan senang atau kecewa seseorang yang diperoleh dari kesan terhadap kinerja atau hasil suatu produk dengan harapan-harapannya (Kotler, 2007). Berdasarkan definisi tersebut, kepuasan adalah fungsi dari kesan kinerja dan harapan. Pasien akan merasa puas apabila kinerja layanan kesehatan yang diperoleh sama atau melebihi harapannya. Ketidakpuasan atau perasaan kecewa pasien akan muncul apabila kinerja layanan kesehatan yang diperoleh tidak sesuai dengan harapannya. Kualitas pelayanan yang baik akan mempengaruhi kepuasan pasien dan mengakibatkan pasien kembali datang untuk menggunakan jasa pelayanan tersebut.

Rumah Sakit Islam Surabaya adalah salah satu rumah sakit swasta dengan klasifikasi Rumah Sakit Umum kelas C. Berkembangnya jumlah rumah sakit di
Surabaya menjadikan Rumah Sakit Islam Surabaya harus mampu untuk bersaing dengan rumah sakit lain karena masyarakat Surabaya memiliki banyak pilihan untuk menentukan rumah sakit mana yang akan mereka pilih. Masyarakat akan memilih rumah sakit yang memberikan kepuasan maksimal bagi mereka. Dalam persaingan yang semakin ketat, salah satu strategi yang dapat digunakan oleh suatu penyedia jasa adalah dengan meningkatkan kualitas pelayanan (Rudy\&Wansley, 1985). Penyedia jasa layanan kesehatan diharuskan untuk meningkatkan kualitas tidak hanya dari sisi teknologi saja tetapi juga pelayanan. Salah satu unsur penting pelayanan di rumah sakit adalah pelayanan farmasi.

Berikut merupakan data sekunder hasil survey awal mengenai kepuasan pasien di Instalasi Farmasi Rumah Sakit Islam Surabaya pada bulan Desember 2015 dan bulan Januari sampai dengan Maret 2016:

Tabel 1.1Hasil survey kepuasanpasien di Instalasi Farmasi RSIS pada bulan Desember 2015 sampai dengan bulan Maret 2016

\begin{tabular}{|c|l|c|c|c|c|}
\hline \multirow{2}{*}{ BULAN } & PERNYATAAN & $\begin{array}{c}\text { Sangat } \\
\text { kurang }\end{array}$ & Kurang & Baik & $\begin{array}{c}\text { Sangat } \\
\text { baik }\end{array}$ \\
\hline \multirow{3}{*}{$\begin{array}{c}\text { DESEMBER } \\
2015\end{array}$} & a. Keramahan petugas & $21 \%$ & $12 \%$ & $50 \%$ & $17 \%$ \\
\cline { 2 - 6 } & b. Kecepatan petugas & $17 \%$ & $35 \%$ & $40 \%$ & $8 \%$ \\
\cline { 2 - 6 } & c. Kelengkapan obat & $17 \%$ & $37 \%$ & $35 \%$ & $12 \%$ \\
\cline { 2 - 6 } & $\begin{array}{c}\text { d. Kejelasan informasi } \\
\text { tentang obat }\end{array}$ & $19 \%$ & $6 \%$ & $56 \%$ & $19 \%$ \\
\hline
\end{tabular}




\begin{tabular}{|c|c|c|c|c|c|}
\hline BULAN & PERNYATAAN & $\begin{array}{l}\text { Sangat } \\
\text { kurang }\end{array}$ & Kurang & Baik & $\begin{array}{c}\text { Sangat } \\
\text { baik }\end{array}$ \\
\hline \multirow{4}{*}{$\begin{array}{l}\text { JANUARI } \\
2016\end{array}$} & a. Keramahan petugas & $14 \%$ & $36 \%$ & $43 \%$ & $7 \%$ \\
\hline & b. Kecepatan petugas & $8 \%$ & $39 \%$ & $47 \%$ & $6 \%$ \\
\hline & c. Kelengkapan obat & $19 \%$ & $57 \%$ & $23 \%$ & $1 \%$ \\
\hline & $\begin{array}{l}\text { d. Kejelasan informasi } \\
\text { tentang obat }\end{array}$ & $16 \%$ & $36 \%$ & $45 \%$ & $3 \%$ \\
\hline \multirow{4}{*}{$\begin{array}{l}\text { FEBRUARI } \\
2016\end{array}$} & a. Keramahan petugas & $21 \%$ & $41 \%$ & $34 \%$ & $5 \%$ \\
\hline & b. Kecepatan petugas & $13 \%$ & $45 \%$ & $35 \%$ & $6 \%$ \\
\hline & c. Kelengkapan obat & $19 \%$ & $65 \%$ & $14 \%$ & $3 \%$ \\
\hline & $\begin{array}{l}\text { d. Kejelasan informasi } \\
\text { tentang obat }\end{array}$ & $5 \%$ & $36 \%$ & $55 \%$ & $4 \%$ \\
\hline \multirow{4}{*}{$\begin{array}{l}\text { MARET } \\
2016\end{array}$} & a. Keramahan petugas & $19 \%$ & $57 \%$ & $23 \%$ & $1 \%$ \\
\hline & b. Kecepatan petugas & $16 \%$ & $36 \%$ & $45 \%$ & $3 \%$ \\
\hline & c. Kelengkapan obat & $16 \%$ & $32 \%$ & $45 \%$ & $7 \%$ \\
\hline & $\begin{array}{l}\text { d. Kejelasan informasi } \\
\text { tentang obat }\end{array}$ & $8 \%$ & $25 \%$ & $58 \%$ & $9 \%$ \\
\hline
\end{tabular}

Sumber: Data Sekunder Unit Humas Rumah Sakit Islam Surabaya

Berdasarkan tabel diatas, maka dapat diketahui bahwa prosentase hasil survey kepuasan pasien di Instalasi Farmasi Rumah Sakit Islam Surabaya mengalami penurunan terutama pada kelengkapan obat.

Kerangka konseptual penelitian ini mengacu pada identifikasi masalah dan tinjauan teoritis yang disusun untuk menggambarkan konsep kepuasan pasien di Instalasi Farmasi Rumah Sakit Islam Surabaya. Peneliti menggunakan teori faktor-faktor pelayanan kesehatan yang dapat mempengaruhi kepuasan pasien dengan 7 faktor untuk mengukur tingkat kualitas pelayanan farmasi di Rumah Sakit Islam Surabaya akan tetapi pada penelitian ini berfokus pada 5 faktor yaitu faktor pelayanan kesehatan yang mempengaruhi kepuasan pasien meliputi faktor kehandalan (reliability), jaminan/kepastian (assurance), bukti fisik/berwujud (tangible), perhatian/empati (emphaty), dan faktor daya tanggap (responsiveness). Hasil pencapaian tingkat kepuasan pasien di Instalasi Farmasi Rumah Sakit Islam Surabaya.Sedangkan untuk faktor pelayanan dan biaya tidak diteliti.

\section{METODE}

Penelitian ini merupakan jenis descriptive research (penelitian deskriptif) yang bertujuan untuk memberikan gambaran tentang kondisi atas objek dalam fakta yang sebenarnya, secara sistematis dan karakteristik dari subjek dan objek tersebut diteliti secara akurat, tepat dan sesuai dengan kejadian yang sebenarnya guna melakukan perbaikan dan peningkatan kegiatan pelayanan kefarmasian. Manfaat dilakukan penelitian deskriptif yaitu hasilnya bisa digunakan peneliti ataupun pelayanan kesehatan 
untuk mendapatkan suatu informasi yang cepat serta relevan mengenai ciri-ciri dari subjek studi dan juga klasifikasi penyakit beserta pengobatannya.

Populasi adalah wilayah generalisasi yang terdiri atas objek/subjek yang mempunyai kualitas dan karakteristik tertentu yang ditetapkan oleh peneliti untuk dipelajari dan kemudian ditarik kesimpulannya (Sugiyono, 2008:115). Populasi dalam penelitian ini adalah seluruh pasien di Instalasi Farmasi Rumah Sakit Islam Surabaya.

Sampel adalah sebagian dari jumlah dan karakteristik yang dimiliki oleh populasi tersebut (Sugiyono, 2008:116) ataupun bagian kecil dari anggota populasi yang diambil menurut prosedur tertentu sehingga mewakili populasinya.Penelitian ini menggunakan non random sampling dengan tekhnik accidental sampling.

Metode penyajian dalam penelitian ini yaitu semua data diolah yang telah terkumpul baik yang diperoleh dari hasil observasi, wawancara ataupun kuesioner selanjutnya dianalisis secara deskriptif. Penyajian dalam bentuk persentase serta dipaparkan dengan menggunakan narasi.

\section{Karakteristik Responden}

Responden dalam penelitian ini adalah 50 orang pasien di Instalasi Farmasi Rumah Sakit Islam Surabaya. Berdasarkan hasil wawancara dan kuisioner, diketahui bahwa dari usia responden di Instalasi
Farmasi Rumah Sakit Islam Surabaya yang paling tua berusia 66 tahun dan yang paling muda berusia 14 tahun.Karakteristik responden tersebut dapat dilihat pada tabel berikut:

Tabel 5.1Distribusi Karakteristik Umur Responden di Instalasi Farmasi Rumah Sakit Islam Surabaya Tahun 2016

\begin{tabular}{|l|c|c|}
\hline \multirow{2}{*}{$\begin{array}{l}\text { Umur } \\
\text { (tahun) }\end{array}$} & \multicolumn{2}{|c|}{$\begin{array}{c}\text { Responden IFRS } \\
\text { RSIS }\end{array}$} \\
\cline { 2 - 3 } & $\mathrm{N}$ & $\%$ \\
\hline$\leq 30$ & 17 & 34 \\
\hline$\geq 31$ & 33 & 66 \\
\hline Total & 50 & 100 \\
\hline
\end{tabular}

Berdasarkan tabel 5.1 diatas dapat diketahui, bahwa sebanyak 34\% responden di Instalasi Farmasi Rumah Sakit Islam Surabaya yang berusia $\leq 30$ tahun dan66\% responden yang berusia $\geq 31$ tahun.

Wawancara selanjutnya mengenai status pasien responden yang dapat dilihat pada tabel:

Tabel 5.2 Distribusi Karakteristik Jenis Kelamin Responden di Instalasi Farmasi RSIS Tahun 2016

\begin{tabular}{|l|c|c|}
\hline \multirow{2}{*}{$\begin{array}{c}\text { Jenis } \\
\text { Kelamin }\end{array}$} & \multicolumn{2}{|c|}{$\begin{array}{c}\text { Responden IFRS } \\
\text { RSIS }\end{array}$} \\
\cline { 2 - 3 } & $\mathrm{N}$ & $\%$ \\
\hline Laki-laki & 17 & 34 \\
\hline Perempuan & 33 & 66 \\
\hline Total & 50 & 100 \\
\hline
\end{tabular}

Berdasarkan tabel diatas dapat diketahui, bahwa responden di Instalasi Farmasi Rumah Sakit Islam Surabaya yang 
berjenis kelamin perempuan lebih banyak yaitu sebanyak 66\% daripada laki-laki yang hanya memiliki prosentase sebesar $34 \%$.

Tabel 5.3 Distribusi Karakteristik Pendidikan Responden di Instalasi Farmasi Rumah Sakit Islam Surabaya Tahun 2016

\begin{tabular}{|l|c|c|}
\hline \multirow{2}{*}{ Pendidikan } & \multicolumn{2}{c|}{$\begin{array}{c}\text { Responden } \\
\text { IFRS RSIS }\end{array}$} \\
\cline { 2 - 3 } & $\mathrm{N}$ & $\%$ \\
\hline SD & 3 & 6 \\
\hline SMP & 3 & 6 \\
\hline SMA/SMK & 29 & 58 \\
\hline $\begin{array}{l}\text { Perguruan } \\
\text { Tinggi }\end{array}$ & 15 & 30 \\
\hline Total & 50 & 100 \\
\hline
\end{tabular}

Karakteristik pendidikan sebagian besar responden di Instalasi Farmasi Rumah Sakit Islam Surabaya adalah SMA/SMK yaitu sebesar 58\% dan Perguruan Tinggi sebesar 30\%. Wawancara selanjutnya mengenai pendapatan responden yang dapat dilihat pada tabel:

Tabel 5.4Distribusi Karakteristik PendapatanResponden di Instalasi Farmasi Rumah Sakit Islam Surabaya Tahun 2016

\begin{tabular}{|c|c|c|}
\hline \multirow[t]{2}{*}{ Pendapatan } & \multicolumn{2}{|c|}{$\begin{array}{l}\text { Responden } \\
\text { IFRS RSIS }\end{array}$} \\
\hline & $\mathrm{N}$ & $\%$ \\
\hline$<$ Rp. 500.000,00 & 2 & 4 \\
\hline $\begin{array}{l}\text { Rp. 500.001- Rp. } \\
2.500 .00 ., 00\end{array}$ & 25 & 50 \\
\hline $\begin{array}{l}\text { Rp. 2.500.001-Rp. } \\
5.000 .000,00\end{array}$ & 9 & 18 \\
\hline$>$ Rp. 5.000.000,00 & 3 & 6 \\
\hline $\begin{array}{l}\text { Tidak memiliki } \\
\text { pendapatan }\end{array}$ & 11 & 22 \\
\hline Total & 50 & 100 \\
\hline
\end{tabular}

Berdasarkan tabel diatas dapat diketahui, bahwasebagian besar responden di Instalasi Farmasi Rumah Sakit Islam Surabaya yang memiliki pendapatan Rp. Rp. 500.001- Rp. 2.500.00.,00 sebanyak $50 \%$. Wawancara selanjutnya mengenai status pasien responden yang dapat dilihat pada tabel:

Tabel 5.5Distribusi Karakteristik Status Responden di Instalasi Farmasi Rumah Sakit Islam Surabaya Tahun 2016

\begin{tabular}{|l|c|c|}
\hline \multirow{2}{*}{ Status Pasien } & \multicolumn{2}{|c|}{$\begin{array}{c}\text { Responden IFRS } \\
\text { RSIS }\end{array}$} \\
\cline { 2 - 3 } & $\mathrm{N}$ & $\%$ \\
\hline Umum & 12 & 24 \\
\hline Asuransi & 1 & 2 \\
\hline BPJS & 37 & 74 \\
\hline Total & 50 & 100 \\
\hline
\end{tabular}

Berdasarkan tabel diatas dapat diketahui, bahwasebagian besar responden di Instalasi Farmasi Rumah Sakit Islam Surabaya berstatus BPJS sebanyak 74\%.

Tabel $\quad 5.6$ Distribusi Karakteristik Pekerjaan Responden di InstalasiFarmasi Rumah Sakit Islam Surabaya Tahun 2016

\begin{tabular}{|l|c|c|}
\hline \multirow{2}{*}{ Pekerjaan } & \multicolumn{2}{|c|}{$\begin{array}{c}\text { Responden } \\
\text { IFRS RSIS }\end{array}$} \\
\cline { 2 - 3 } & $\mathrm{N}$ & $\%$ \\
\hline $\begin{array}{l}\text { PNS/TNI/ } \\
\text { POLRI }\end{array}$ & 4 & 8 \\
\hline Swasta & 21 & 42 \\
\hline Wiraswasta & 11 & 22 \\
\hline Pensiunan & 2 & 4 \\
\hline $\begin{array}{l}\text { Ibu Rumah } \\
\text { Tangga }\end{array}$ & 6 & 12 \\
\hline $\begin{array}{l}\text { Siswa/Mahasis } \\
\text { wa }\end{array}$ & 6 & 12 \\
\hline Total & 50 & 100 \\
\hline
\end{tabular}


Berdasarkan tabel diatas dapat diketahui, bahwa responden di instalasi Farmasi Rumah Sakit Islam Surabaya yang memiliki pekerjaan swasta sebanyak $42 \%$ dan wiraswasta dengan prosentase sebesar $22 \%$.

\section{HASIL PENELITIAN}

Berdasarkan hasil wawancara dengan 50 responden melalui kuesioner di Instalasi Farmasi Rumah Sakit Islam Surabaya maka didapatkan hasil sebagai berikut:

Tabel 5.7 Distribusi Hasil Kepuasan Pasien/Responden di Instalasi Farmasi Rumah Sakit Islam Surabaya Tahun 2016

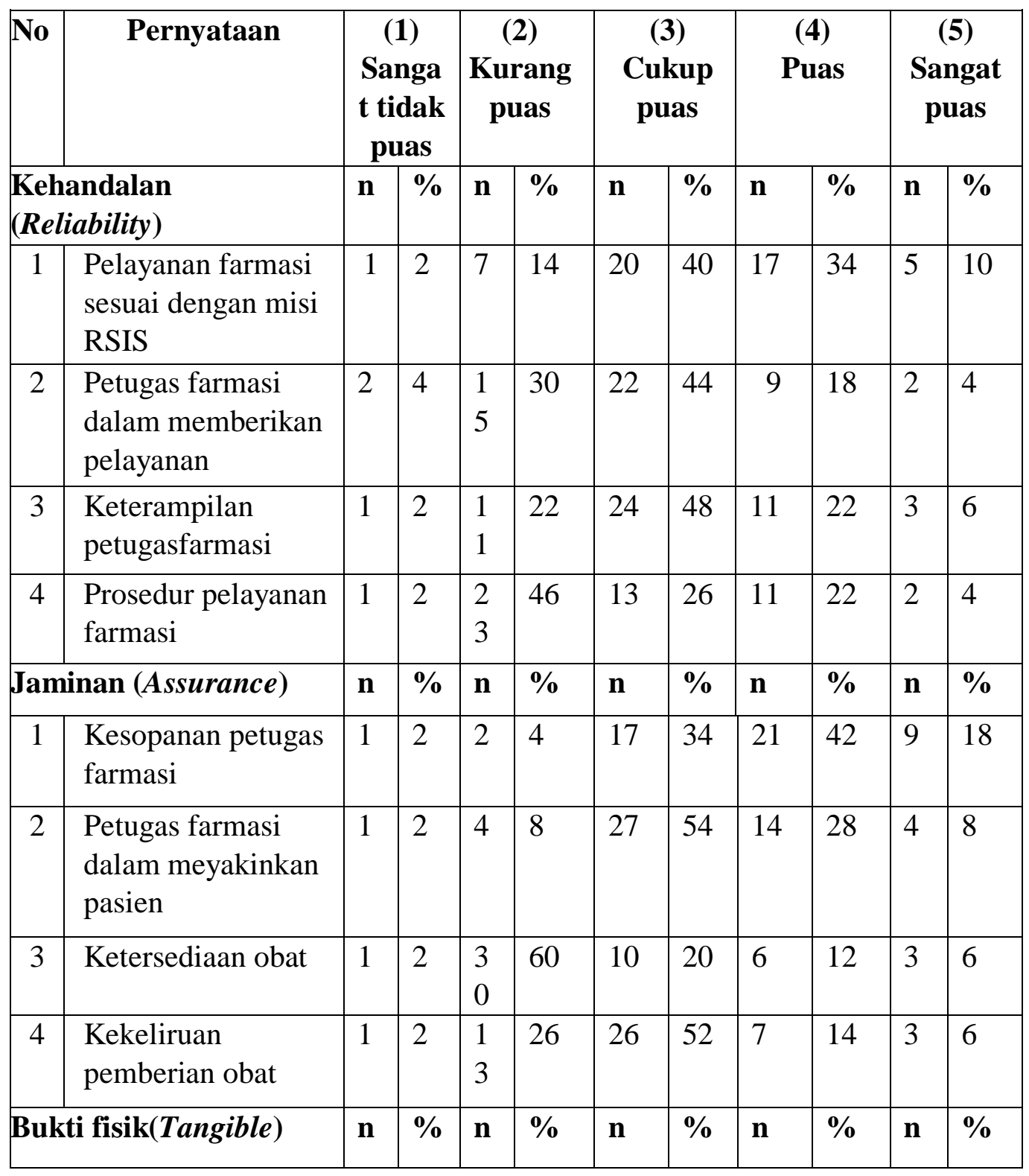




\begin{tabular}{|c|c|c|c|c|c|c|c|c|c|c|c|}
\hline 1 & $\begin{array}{l}\text { Tersedianya sarana } \\
\text { (berupa speaker } \\
\text { untuk memanggil } \\
\text { pasien) }\end{array}$ & 1 & 2 & 16 & 32 & 10 & 20 & 15 & 30 & 8 & 16 \\
\hline 2 & $\begin{array}{l}\text { Kebersihan di } \\
\text { Instalasi Farmasi }\end{array}$ & 1 & 2 & 9 & 18 & 14 & 28 & 17 & 34 & 9 & 18 \\
\hline 3 & $\begin{array}{l}\text { Ketersediaan kursi } \\
\text { tunggu }\end{array}$ & 1 & 2 & 8 & 16 & 13 & 26 & 19 & 38 & 9 & 18 \\
\hline 4 & $\begin{array}{l}\text { Kenyamanan pada } \\
\text { ruang tunggu }\end{array}$ & 1 & 2 & 12 & 24 & 18 & 36 & 14 & 28 & 5 & 10 \\
\hline \multicolumn{2}{|c|}{ Empati (Emphaty) } & $\mathbf{n}$ & $\%$ & $\mathbf{n}$ & $\%$ & $\mathbf{n}$ & $\%$ & $\mathbf{n}$ & $\%$ & $\mathbf{n}$ & $\%$ \\
\hline 1 & $\begin{array}{l}\text { Petugas farmasi } \\
\text { bersikap adil dan } \\
\text { tidak membedakan } \\
\text { pasien }\end{array}$ & 1 & 2 & 2 & 4 & 18 & 36 & 23 & 46 & 6 & 12 \\
\hline 2 & $\begin{array}{l}\text { Kesabaran petugas } \\
\text { farmasi }\end{array}$ & 1 & 2 & 13 & 26 & 22 & 44 & 10 & 20 & 4 & 8 \\
\hline 3 & $\begin{array}{l}\text { Petugas farmasi } \\
\text { memberikan } \\
\text { perhatian pribadi } \\
\text { kepada pasien yang } \\
\text { membutuhkan } \\
\text { pelayanan segera }\end{array}$ & 1 & 2 & 25 & 50 & 10 & 20 & 10 & 20 & 4 & 8 \\
\hline 4 & $\begin{array}{l}\text { Petugas farmasi } \\
\text { memberikan solusi } \\
\text { terkait indikasi } \\
\text { obat }\end{array}$ & 1 & 2 & 12 & 24 & 18 & 36 & 15 & 30 & 4 & 8 \\
\hline \multicolumn{2}{|c|}{\begin{tabular}{|l} 
Daya tanggap \\
(Responsiveness)
\end{tabular}} & $\mathbf{n}$ & $\%$ & n & $\%$ & $\mathbf{n}$ & $\%$ & $\mathbf{n}$ & $\%$ & $\mathbf{N}$ & $\%$ \\
\hline 1 & $\begin{array}{l}\text { Kemampuan } \\
\text { petugas farmasi } \\
\text { memberikan } \\
\text { kejelasan informasi } \\
\text { tentang obat }\end{array}$ & 1 & 2 & 12 & 24 & 15 & 30 & 18 & 36 & 4 & 8 \\
\hline 2 & $\begin{array}{l}\text { Keramahan petugas } \\
\text { farmasi }\end{array}$ & 2 & 4 & 24 & 48 & 10 & 20 & 9 & 18 & 5 & 10 \\
\hline 3 & $\begin{array}{l}\text { Kecekatan petugas } \\
\text { farmasi }\end{array}$ & 1 & 2 & 15 & 30 & 16 & 32 & 14 & 28 & 4 & 8 \\
\hline 4 & $\begin{array}{l}\text { Waktu tunggu } \\
\text { pengambilan obat }\end{array}$ & 2 & 4 & 37 & 74 & 6 & 12 & 3 & 6 & 2 & 4 \\
\hline
\end{tabular}

Sumber: Data Primer Tahun 2016 
Berdasarkan tabel diatas diketahui, bahwa prosentase hasil wawancara dengan responden melalui kuesioner kepuasan pasien di Instalasi Farmasi Rumah Sakit Islam Surabaya mengalami prosentase tinggi yang menyatakan kurang puas terutama pada indikator keramahan petugas farmasi, waktu tunggu pengambilan obat, ketersediaan obat, serta petugas memberikan perhatian pribadi kepada pasien yang membutuhkan pelayanan segera.

\section{PEMBAHASAN}

A. Faktor kehandalan (reliability)

Menurut Erna Juliana (2008), kehandalan merupakan tanggapan pasien terhadap kinerja petugas kesehatan dalam hal akurasi data dan pelayanan yang sesuai janji sehingga memuaskan.

Secara keseluruhan kepuasan pasien terhadap faktor kehandalan di Instalasi Farmasi Rumah Sakit Islam Surabaya termasuk dalam kategori baik/memuaskan dengan prosentase sebesar 69,5\%. Akan tetapi pada indikator prosedur pelayanan farmasi Rumah Sakit Islam Surabaya perlu adanya perhatian khusus karena masih terdapat responden yang menyatakan kurang. Hal ini disebabkan adanya persepsi responden yang belum memahami tentang prosedur yang harus dilakukannya. Sehingga dianggap bahwa prosedur itu dinyatakan berbelit-belit.

\section{B. Faktor jaminan/kepastian (assurance)}

Menurut Erna Juliana (2008), jaminan keamanan yang ditunjukkan oleh petugas kesehatan (assurance), ketepatan jadwal pemeriksaan, dan kunjungan dokter juga termasuk dalam faktor ini. Jaminan pelayanan kesehatan merupakan salah satu pendekatan atau upaya yang sangat mendasar dalam memberikan pelayanan kepada pasien.

Secara keseluruhan kepuasan pasien terhadap faktor jaminan/kepastian di Instalasi Farmasi Rumah Sakit Islam Surabaya termasuk dalam kategori baik/memuaskan dengan prosentase sebesar 73,5\%. Akan tetapi pada indikator ketersediaan obat perlu adanya perhatian dan perbaikan karena memiliki prosentase sebesar 62\% dengan penilaian kurang memuaskan. Hal ini menyatakan, bahwa tingkat ketersediaan obat di Instalasi Farmasi Rumah Sakit Islam Surabaya masih kurang, karena terdapat pasien yang menerima jumlah obat tidak sesuai berdasarkan resep dokter.

Adapun pada indikator tingkat kekeliruan pemberian obat hakekatnya tidak ada, akan tetapi hanya terdapat pemahaman terhadap nama obat, rupa obat, dosis obat, kemasan obat, dan produk obat dari suatu institusi industri yang tidak sesuai dengan harapan responden namun hal tersebut telah teratasi dengan cepat. 
C. Faktor bukti fisik/berwujud (tangible)

Menurut Parasuman, dkk (1998), dimensi bukti fisik/berwujud (tangible) didefinisikan sebagai penampilan fasilitasperalatan dan petugas yang memberikan pelayanan jasa karena suatu servis jasa tidak dapat dilihat, dicium, diraba atau didengar maka aspek bukti fisik/berwujudmenjadi sangat penting sebagai ukuran terhadap pelayananjasa.

Secara keseluruhan kepuasan pasien terhadap faktor bukti fisik/berwujud di Instalasi Farmasi Rumah Sakit Islam Surabaya termasuk dalam kategori baik/memuaskan dengan prosentase sebesar 75,5\%. Hal ini menyatakan, bahwa kepuasan pasien akan bukti fisik di Instalasi Farmasi Rumah Sakit Islam Surabaya sudah baik dan sangat memadai.

D. Faktor perhatian/empati(emphaty)

Menurut Lupiyoadi (2006:182), perhatian/empati (empathy) adalah kesediaan untuk peduli dan memberikan perhatian pribadi kepada pengguna jasa. Pelayanan yang empatik sangatmemerlukan sentuhan/perasaan pribadi. Faktor empati adalah dimensi yang memberikan peluang besar untuk menciptakan pelayanan yang "surprice" yaitu sesuatu yang tidak diharapkan pengguna jasa tetapi ternyata diberikan oleh penyedia jasa. Faktor empati ini merupakan penggabungan dari aspek:
1. Akses (access) meliputi kemudahan memanfaatkan jasa yang ditawarkan penyedia jasa.

2. Komunikasi (communication), yaitu merupakan kemampuan melakukan komunikasi untuk menyampaikan informasi kepada konsumen atau memperoleh masukan dari konsumen.

3. Pemahaman pada konsumen (understanding the customer), meliputi usaha penyedia jasa untuk mengetahui dan memahami kebutuhan dan keinginan konsumen.

Secara keseluruhan kepuasan pasien terhadap faktor perhatian/empati di Instalasi Farmasi Rumah Sakit Islam Surabaya termasuk dalam kategori baik/memuaskan dengan prosentase sebesar $72 \%$. Akan tetapi pada indikator petugas farmasi dalam memberikan perhatian pribadi kepada pasien yang membutuhkan pelayanan segera dapat dikategorikan sebagian besar responden menyatakan sangat tidak puas dengan prosentase sebesar 52\%. Hal ini menyatakan, bahwa petugas farmasi belum maksimal memberikan perhatian pribadinya ketika pasien membutuhkan pelayanan segera karena kurangnya rasa tenggang rasa yang dimiliki oleh petugas dan disertai belum adanya pelatihan tentang kepribadian dari pihak manajemen Rumah sakit islam Surabaya. 
E. Faktor daya tanggap (responsiveness)

Menurut Parasuman, dkk (1998), daya tanggap (responsiveness) adalah kemauan untuk membantu dan memberikan jasa dengan cepat kepada konsumen yang meliputi kesigapan tenaga kerja dalam melayani konsumen, kecepatan tenaga kerja dalam menangani transaksi dan penanganan atas keluhan konsumen. Faktor daya tanggap merupakan faktor yang bersifat paling dinamis. Hal ini dipengaruhi oleh perkembangan teknologi. Salah satu contoh aspek daya tanggap dalam pelayanan adalah kecepatan.

Secara keseluruhan kepuasan pasien terhadap faktor daya tanggap di Instalasi Farmasi Rumah Sakit Islam Surabaya termasuk dalam kategori cukup baik/cukup memuaskan dengan prosentase sebesar 53\%. Akan tetapi pada indikator keramahan petugas yang memiliki prosentase sebesar 52\% dan waktu tunggu pengambilan obat sebesar $78 \%$ dapat dikategorikan sebagian besar responden menyatakan sangat tidak puas. Hal ini menyatakan, bahwa tingkat keramahan petugas farmasi Rumah Sakit Islam Surabaya kurang baik karena memiliki berbagai faktor salah satunya disebabkan oleh pekerjaan yang menumpuk.

Sedangkan untuk waktu tunggu pengambilan obat di Instalasi Farmasi Rumah Sakit Islam Surabaya termasuk dalam kategori cukup lama. Sehingga dapat dianalogikan bahwa waktu tunggu di Instalasi Farmasi Rumah Sakit Islam Surabaya kurang baik.

\section{KESIMPULAN}

Berdasarkan hasil penelitian dan pembahasan pada bab sebelumnya dapat disusun beberapa kesimpulan sebagai berikut:

a. Tingkat kepuasan pasien pada Instalasi Farmasi Rumah Sakit Islam Surabaya berdasarkan faktor kehandalan (reliability) menunjukkan bahwa sebagian besar pasien merasa puas akan pelayanan yang diberikan oleh petugas farmasi kepada pasien yaitu sebanyak 69,5\%.

b. Tingkat kepuasan pasien pada Instalasi Farmasi Rumah Sakit Islam Surabaya berdasarkan faktor jaminan/kepastian (assurance) dapat dikategorikan baik karena terdapat $73,5 \%$ responden yang menyatakan puas. Akan tetapi pada indikator ketersediaan obat menunjukkan bahwa sebagian besar pasien merasa kurang puas yang memiliki prosentase sebesar 62\%. Hal ini disebabkan karena pasien menerima jumlah obat yang tidak sesuai dengan resep dokter.

c. Tingkat kepuasan pasien pada Instalasi Farmasi Rumah Sakit Islam Surabaya berdasarkan bukti fisik/berwujud (tangible) menunjukkan bahwa sebagian besar 
pasien merasa puas (75,5\%) akan sarana dan prasarana yang terdapat di Instalasi Farmasi Rumah Sakit Islam Surabaya. Sehingga faktor bukti fisik/berwujud (tangible) dapat dikategorikan sudah baik dan sangat memadai.

d. Tingkat kepuasan pasien pada Instalasi Farmasi Rumah Sakit Islam Surabaya berdasarkan faktor perhatian/empati (emphaty) menunjukkan bahwa sebagian besar pasien merasa puas akan sikap, perhatian, dan kesopanan petugas farmasi yang telah diberikan kepada pasien yaitu sebesar 72\%. Namun pada indikator petugas memberikan perhatian pribadi kepada pasien yang membutuhkan pelayanan segera yang merupakan salah satu indikator dari faktor perhatian/empati, menyatakan bahwa pasien kurang puas akan hal tersebut karena pada penelitian ini diperoleh prosentase sebesar $52 \%$.

e. Tingkat kepuasan pasien pada Instalasi Farmasi Rumah Sakit Islam Surabaya berdasarkan faktor daya tanggap menunjukkan bahwa sebagian besar pasien merasa puas akan pelayanan yang diberikan oleh petugas farmasi yaitu sebesar 53\%. Akan tetapi terdapat 2 indikator yang memiliki prosentase tertinggi dengan kategori kurang puas yakni keramahan petugas dan waktu tunggu pengambilan obat yang dapat dikatakan lama. Hal tersebut disebabkan adanya masalah pribadi, job disc petugas farmasi yang overload, banyaknya resep sehingga dapat membuat petugas lelah, kurangnya SDM.

Pada umumnyapelayanan yang diberikan di Instalasi Farmasi Rumah Sakit Islam Surabaya menunjukkan peningkatan kepuasan para pasien dari 5 (lima) faktor pelayanan yang diberikan. Akan tetapi ada beberapa catatan yang harus mendapatkan perhatian dari pihak manajemen Rumah Sakit Islam Surabaya pada umumnya dan Instalasi Farmasi pada khususnya terutama pada faktor jaminan/kepastian (assurance) ditemukan pasien merasa kurang puas terhadap ketersediaan obat.

Adapun pada faktor perhatian/empati (emphaty) ditemukan pasien merasa kurang puas terhadap petugas yang kurang memberikan perhatian pribadi pada pelayanan. Begitu pula pada faktor daya tanggap (responsiveness) masih dijumpai pasien yang kurang puas atas pelayanan yang diberikan berkenaan dengan keramahan dari petugas farmasi serta waktu tunggu untuk pengambilan obat. Namun demikian semua itu atas ketidakpuasan pasien terhadap sebagian kecil dari faktor pelayanan tersebut hakekatnya dapat dibenahi. 
SARAN

1. Dilakukan pelatihan soft skillberupa pelatihan service excellence dan pelatihan kepribadian secara periodik bagi petugas farmasi Rumah Sakit Islam Surabaya dan menerapkan 3S (salam, senyum, sapa).

2. Dilakukan pelatihan kecepatan waktu menggunakan pengukuran waktu tertentu dengan model simulasi yang dilakukan oleh petugas farmasi agar dapat mencapai pelayanan farmasi secara optimal yang tidak melebihi standar respond time.Melakukan pendataan secara konkrit atas ketersediaan obat berdasarkan tingkat kebutuhan pasien baik yang bersifat mendesak maupun biasa dengan dilakukan cara pemesanan obat fast moving lebih banyak atau ditambahkan jadwal pemesanan obat ke Pedagang Besar Farmasi (PBF).

\section{DAFTAR PUSTAKA}

Depkes, RI., 1992. Peraturan Menteri Kesehatan RI Nomor 983/Menkes/SK/XI/1992 tentang Pedoman Organisasi Rumah Sakit Umum. Jakarta: Depkes RI.

Juliana, Erna, 2008. Manajemen Pelayanan Kebidanan. Jakarta: EGC.

Keputusan Menteri Kesehatan Nomor 1333/Menkes/SK/XII/1999 tentang Standar Pelayanan Rumah Sakit.
Kotler, P., 2007. Manajemen Pemasaran Cetakan Pertama. Edisi Bahasa Indonesia. Jakarta: PT. Indeks.

Lupiyoadi, Hamdani, 2006. Manajemen Pemasaran Jasa. Edisi Kedua. Jakarta: Penerbit Salemba Empat.

Parasuraman A., Zeithaml, Valerie A., Berry, Leonard L., 1985. A Conceptual Model of Service Quality and its Implications for Future Research. Journal of Marketing Vol 49.

Peraturan Menteri Kesehatan Republik Indonesia Nomor 58 tahun 2014 tentang Standar Pelayanan Kefarmasian di Rumah Sakit.

Peraturan Pemerintah Republik Indonesia Nomor 51 Tahun 2009 tentang Pekerjaan Kefarmasian.

Rudy M. J., Wansley H. B., 1985. The Merrrill Lynch Quality Programs. In Services Marketing In A Changing Environment. Chicago:American.

Shi, L. dan Singh, D., 2005, Essentials of the U. S. health care system 27, M. A.

Siregar, Charles. JP., 2004. Farmasi Rumah Sakit Teori dan Penerapan Cetakan Kesatu.Jakarta: Penerbit Buku Kedokteran EGC.

Sugiyono, 2008. Metodologi Penelitian Bisnis. Cetakan Kedua Belas. Bandung: Alfabeta.

Undang-Undang Republik Indonesia Nomor 44 Tahun 2009 tentang Rumah Sakit. 